\title{
SLC30A10 mutation involved in parkinsonism results in manganese accumulation within nano- vesicles of the Golgi apparatus
}

Asuncion Carmona ${ }^{1,2, *}{ }^{,}$, Charles E. Zogzas ${ }^{3}$, Stéphane Roudeau ${ }^{1,2}$, Francesco Porcaro $^{1,2}$, Jan Garrevoet ${ }^{4}$, Kathryn M. Spiers ${ }^{4}$, Murielle Salomé ${ }^{5}$, Peter Cloetens $^{5}$, Somshuvra Mukhopadhyay ${ }^{3}$ and Richard Ortega ${ }^{1,2, *}$

\author{
${ }^{1}$ Chemical Imaging and Speciation, CENBG, University of Bordeaux, UMR 5797, 33175 Gradignan, \\ France \\ ${ }^{2}$ CNRS, IN2P3, CENBG, UMR 5797, 33175 Gradignan, France \\ ${ }^{3}$ Division of Pharmacology \& Toxicology; Institute for Cellular \& Molecular Biology and Institute \\ for Neuroscience, University of Texas, 78712 Austin, USA. \\ ${ }^{4}$ Deutsches Elektronen Synchrotron DESY, Notkestr. 85, Hamburg, 22607, Germany \\ ${ }^{5}$ European Synchrotron Radiation Facility, Grenoble, France
}

Citation:

ACS Chemical Neuroscience 201910 (1), 599-609

DOI: $10.1021 /$ acschemneuro.8b00451 


\begin{abstract}
Manganese (Mn) is an essential metal that can be neurotoxic when elevated exposition occurs leading to parkinsonian-like syndromes. Mutations in the Slc30al0 gene have been identified in new forms of familial parkinsonism. SLC30A10 is a cell surface protein involved in the efflux of Mn protecting the cell against Mn toxicity. Disease causing mutations block the efflux activity of SLC30A10, resulting in Mn accumulation. Determining the intracellular localization of Mn when disease-causing SLC30A10 mutants are expressed is essential to elucidate the mechanisms of $\mathrm{Mn}$ neurotoxicity. Here, using organelle fluorescence microscopy and synchrotron X-ray fluorescence (SXRF) imaging we found that Mn accumulates in the Golgi apparatus of human cells transfected with the disease-causing SLC30A10- $\Delta 105-107$ mutant under physiological conditions and after exposure to Mn. In cells expressing the wild-type SLC30A10 protein, cellular Mn content was low after all exposure conditions, confirming efficient Mn efflux. In non-transfected cells that do not express endogenous SLC30A10, and in mock transfected cells, Mn was located in the Golgi apparatus, similarly to its distribution in cells expressing the mutant protein, confirming deficient Mn efflux. The newly developed SXRF cryogenic nano-imaging ( $<50 \mathrm{~nm}$ resolution) indicated that $\mathrm{Mn}$ was trapped in single vesicles within the Golgi apparatus. Our results confirm the role of SLC30A10 in Mn efflux and the accumulation of $\mathrm{Mn}$ in cells expressing the disease causing SLC30A10- $\Delta 105-107$ mutation. Moreover, we identified sub-organelle Golgi nano-vesicles as the main compartment of $\mathrm{Mn}$ accumulation in SLC30A10 mutants suggesting interactions with the vesicular trafficking machinery as a cause of the disease.
\end{abstract}

Key words: parkinsonism, manganese, SLC30A10, Golgi, synchrotron, X-ray fluorescence 


\section{INTRODUCTION}

Manganese (Mn) is an essential metal required for the activity of numerous enzymes in man such as mitochondrial superoxide dismutase, pyruvate-carboxylase, liver arginase, and in many others enzymatic systems including transferases, hydrolases, dehydrogenases, synthetases and lyases (1-3). However, elevated levels of Mn are toxic, especially towards the central nervous system (1). At the organism level, when Mn increases, the metal accumulates in the brain, primarily in the basal ganglia, and induces a parkinsonian-like neurotoxic syndrome. Mninduced neurotoxicity has historically been reported in individuals exposed to elevated levels of the metal from occupational sources $(1,4)$. Exposure to elevated Mn from the environment has also been implicated in the onset of Mn neurotoxicity $(4,5)$. Understanding the mechanisms by which elevated Mn levels induces toxicity is an essential step for the development of effective therapeutic strategies.

In comparison to other essential metals such as iron, copper or zinc, the cellular processes regulating $\mathrm{Mn}$ homeostatis are not yet very well characterized (3). In particular it is only recently that important $\mathrm{Mn}$ transport proteins have been identified such as the solute carrier family 30 member 10 (SLC30A10) involved in Mn efflux (6-8), or the solute carrier family 39 member 14 (SLC39A14) that mediates Mn influx (9). In 2012, mutations in SLC30A10 were identified to induce the first inherited disorders of Mn neurotoxicity $(6-8,10)$. Recent studies indicate that the wild-type SLC30A10 protein localizes to the cell surface and mediates Mn efflux; this activity reduces intracellular Mn levels and protects against Mn toxicity $(11,12)$. In contrast, a large number of disease-causing mutations, such as deletion of amino acids 105-107 in SLC30A10, trap the transporter in the endoplasmic reticulum and block its capability to mediate Mn efflux (11). Familial cases of Parkinsonism which exhibit SLC30A10 mutations can be due to Mn toxicity and accumulation during the life time. In human cells and Caenorhabditis elegans, over-expression of SLC30A10 wild-type, but not disease causing mutants, reduces Mn levels and protects against Mn toxicity $(11,13)$. In contrast, depletion of SLC30A10 using siRNA enhances Mn levels and induces Mn toxicity (11). Similarly, Slc30a10 ${ }^{-/}$mice exhibit elevated tissue Mn levels and develop severe Mn toxicity that can be rescued by providing animals a reduced Mn diet (14). Overall, SLC30A10 plays a pivotal role in regulating Mn homeostasis at the cellular and organismal level, and understanding the means by which mutations in SLC30A10 alter cellular Mn homeostasis is expected to enhance understanding of the principles underlying Mn toxicity itself. 
How Mn transporters regulate uptake and efflux of Mn into the cells versus Mn subcellular distribution is not yet well known (3). A key step in understanding the molecular mechanisms of metal toxicity is determining the subcellular distribution of the metal being studied under basal conditions and when intracellular levels increase. Molecular targets of metal toxicity are likely to reside in organelles that accumulate the metal under conditions of toxicity. Addressing this fundamental question has proved to be extremely challenging for Mn because Mn-specific cellular sensors do not exist. Consequently, mechanisms of Mn toxicity are largely unclear, and Mn neurotoxicity, due to elevated exposure or secondary to mutations in SLC30A10, has no treatment.

The goal of this study was to address the fundamental issue of the role of SLC30A10 in influencing intracellular $\mathrm{Mn}$ accumulation. For this, we used organelle fluorescence microscopy and Synchrotron X-Ray Fluorescence (SXRF) imaging to determine Mn distribution in HeLa cells that were either untransfected/mock transfected, or that expressed either SLC30A10 wild-type or the disease-causing 105-107 mutant. Prior studies show that HeLa cells do not express endogenous SLC30A10 (11, 13, 15). Moreover, function of SLC30A10 wild-type and disease-causing mutants expressed in HeLa cells are comparable to the ones found in hepatic and neuronal cell-lines $(11,16)$. Thus, HeLa cells provided a manipulate-able system that would provide physiologically relevant results. The facility at DESY enabled fast cell imaging at sub-micrometric $(700 \mathrm{~nm})$ resolution and allowed us to image many cells at different culture conditions (varying $\mathrm{Mn}$ concentration and protein expression). The ESRF facility enabled high nanometric resolution imaging, allowing us to image cells with a higher spatial resolution $(50 \mathrm{~nm})$. We discovered that in untransfected HeLa cells, as well as in cells expressing SLC30A10- $105-107, \mathrm{Mn}$ accumulated in the Golgi apparatus under basal and elevated exposure conditions. In contrast, Mn levels were very low in cells expressing SLC30A10-WT. These results imply that the Golgi apparatus is the primary organelle that is impacted by Mn accumulation. Additionally, high resolution imaging revealed that sub-organelle Golgi vesicles were the main compartment of Mn accumulation in cells expressing SLC30A10. It is known that Mn alters trafficking of the Golgi protein GPP130 (1719). Our findings raise the exciting possibility that changes in vesicular trafficking induced by Mn may, in fact, play a causal role in the onset and progression of Mn toxicity. 


\section{RESULTS}

\section{Effect of $\Delta 105-107$ mutation on SLC30A10 localization, Mn content and Mn cytotoxicity.}

HeLa cells were transfected with a GFP (Green Fluorescence Protein) construction tagged to SLC30A10-WT protein or to SLC30A10-A105-107 mutant. As previously showed (11) SLC30A10-WT is a cell surface protein but SLC30A10- $\triangle 105-107$ mutant is trapped within the endoplasmic reticulum (ER) (Fig. 1 A and B). In cells expressing the fluorescent SLC30A10WT protein, a cell membrane distribution is observed while in cells expressing the fluorescent SLC30A10- 1 105-107 mutant a strong correlation with ER calnexin is measured with a 0.80 Pearson's coefficient for colocalization (Fig. 1A). A FLAG-tag immunofluorescence microscopy experiment confirmed the specific cell surface distribution of the wild type protein and ER distribution of the $\Delta 105-107$ mutant (Fig. 1B). HeLa cells transfected with the SLC30A10-WT construction and exposed to $500 \mu \mathrm{M}$ Mn showed a lower intracellular Mn content than control cells expressing a mock construction (Rab5-GFP), while cells transfected with the SLC30A10-A105-107 mutant construction displayed a similar intracellular Mn distribution compared to controls (Fig. $1 \mathrm{C}$ and D). In terms of cytotoxicity, the expression of the wild-type SLC30A10 protein protected the cells from Mn toxicity compared to controls, while the expression of the SLC30A10- $\Delta 105-107$ mutant resulted in a comparable sensitivity towards Mn toxicity than controls (Fig. 1E). Mn concentrations corresponding to $25 \%$ and $50 \%$ decrease of cell viability were found respectively around $250 \mu \mathrm{M}$ and $500 \mu \mathrm{M}$ after $16 \mathrm{~h} \mathrm{Mn}$ exposure (Fig 1E). For SXRF experiments, cells were exposed to 250 and $500 \mu \mathrm{M}$ of Mn but only during $4 \mathrm{~h}$ to limit cytotoxic effects while allowing the detection of Mn. Microscopic examination of the cells before SXRF analyses did not reveal visible morphological toxic effects. 


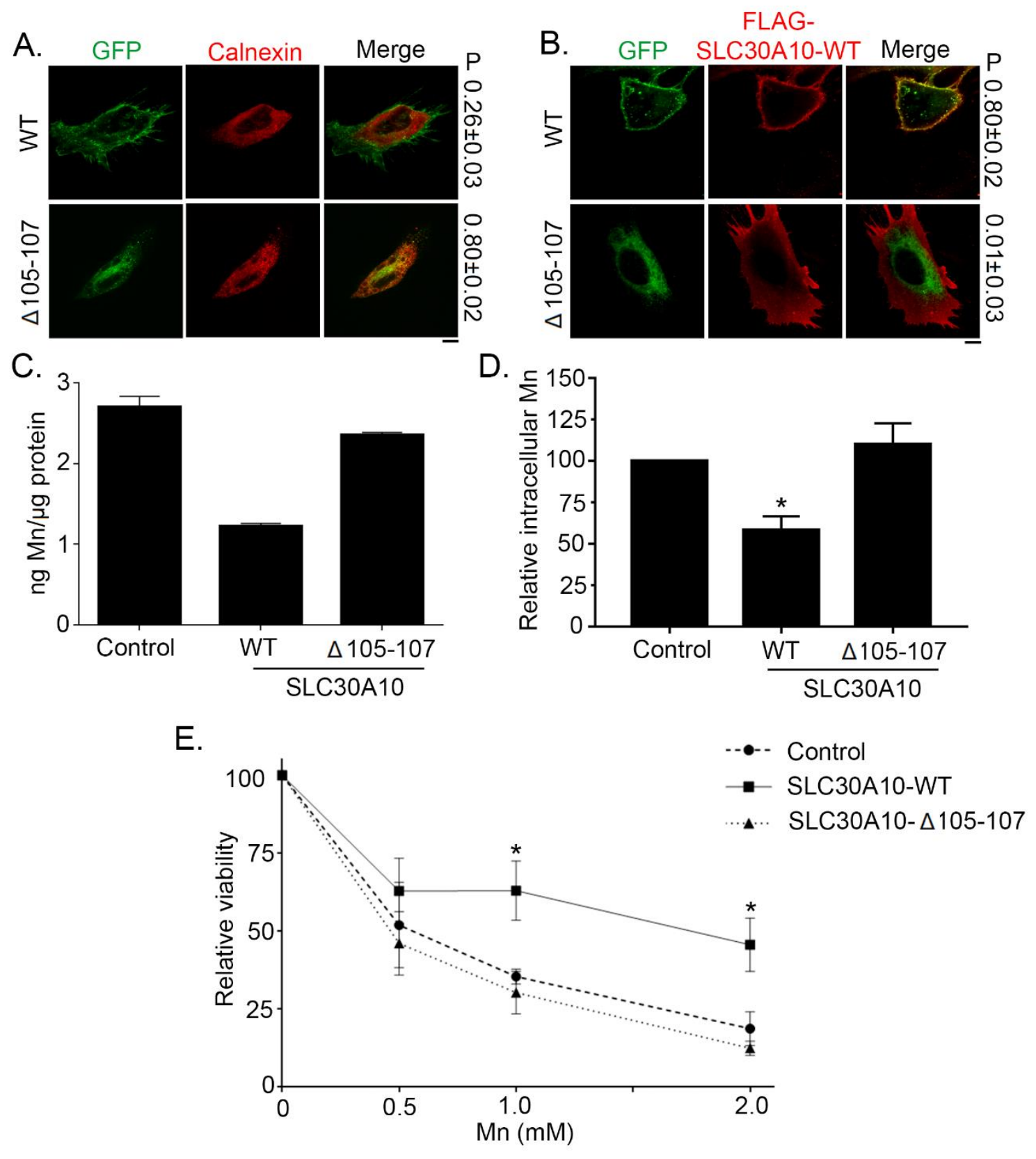

Figure 1. SLC30A10-WT-GFP traffics to the cell surface and protects against Mn toxicity whereas SLC30A10-4105-107-GFP is trapped within the endoplasmic reticulum and unable to protect. (A). HeLa cells were transfected with indicated GFP-tagged SLC30A10 constructs. Two days after transfection, cultures were processed for immunofluorescence. SLC30A10 was detected using GFP fluorescence, and a polyclonal antibody against calnexin was used to demarcate the endoplasmic reticulum. P represents the Pearson's coefficient for colocalization between GFP and calnexin (mean \pm SE; $\mathrm{n}=10$ cells per SLC30A10 construct). Scale bar, 10 $\mu \mathrm{m}$. (B). HeLa cells were co-transfected with GFP-tagged SLC30A10-WT or $-\Delta 105-107$ constructs and FLAG-tagged SLC30A10-WT. Two days after transfection, cells were processed to detect GFP and FLAG. P represents the Pearson's coefficient for colocalization 
between GFP and FLAG (mean \pm SE; $\mathrm{n}=10$ cells per SLC30A10-GFP construct). Scale bar, $10 \mu \mathrm{m}$. (C and D). HeLa cells were transfected with a control construct (Rab5-GFP), SLC30A10-WT-GFP or SLC30A10-_105-107-GFP. Two days after transfection, cells were treated with $500 \mu \mathrm{M}$ Mn for $16 \mathrm{~h}$. The absolute level of intracellular Mn was then measured using ICP-MS and normalized to total protein. Data from one representative experiment are depicted in Panel C; error bars depict SD from three ICP-MS runs. Analysis from three independent experiments is presented in Panel D (mean $\pm \mathrm{SE} ; * \mathrm{p}<0.05$ between WT and other groups using one way ANOVA and Tukey Kramer post hoc test). (E). HeLa cells were transfected as described in Panels C and D above. Two days after transfection, cells were treated with indicated amounts of Mn for $16 \mathrm{~h}$. Cell viability was then assessed using the MTT assay. For each transfection condition, viability at $0 \mathrm{mM}$ Mn was set to 100 and used to calculate the percent viability after $\mathrm{Mn}$ treatment (mean $\pm \mathrm{SE} ; \mathrm{n}=3 ;{ }^{*} \mathrm{p}<0.05$ for the difference between the viability of SLC30A10-WT-expressing cells and other groups at indicated concentrations using two-way ANOVA and Tukey Kramer post hoc test).

\section{Manganese accumulates in the Golgi apparatus of HeLa cells not expressing SLC30A10.}

HeLa cells do not express endogeneously the solute carrier protein SLC30A10 involved in the efflux of Mn $(11,13,15)$. HeLa cells exposed to increasing concentrations of Mn were imaged in a correlative epifluorescence / synchrotron XRF microscopy approach to identify which organelles were responsible for intracellular Mn storage, as previously described for other cells $(20,21)$. SXRF imaging at sub-micrometric resolution, $700 \mathrm{~nm}$ beam size, was performed at beamline P06, PETRA III synchrotron, in Hamburg, Germany (22). Analyses were conducted at room temperature on cryofixed freeze dried cells. The intracellular element potassium is a good indicator of the correct preservation of the cellular morphology and can be used for SXRF imaging to locate the cell position and to perform element/organelle correlative imaging (20, 23, 24). Mn was close to the SXRF limit of detection in cells exposed to a physiological concentration of Mn, without adding $\mathrm{Mn}$ to the cell culture medium (Fig. 2A). Correlative SXRF and organelle fluorescence imaging revealed that Mn accumulates in the Golgi apparatus of non transfected HeLa cells after exposure to 250 and $500 \mu \mathrm{M} \mathrm{MnCl}_{2}$ for $4 \mathrm{~h}$ (Fig. $2 \mathrm{~B}$ and C). Similar results are found when HeLa cells are mock-transfected with Rab5-GFP, a controlexpression vector, with the accumulation of $\mathrm{Mn}$ in the Golgi apparatus of cells exposed to 250 and $500 \mu \mathrm{M}$ of $\mathrm{MnCl}_{2}$ for $4 \mathrm{~h}$ (Fig. 3A and 4A). These results indicates that the transfection protocol does not modify the intracellular distribution of $\mathrm{Mn}$. 


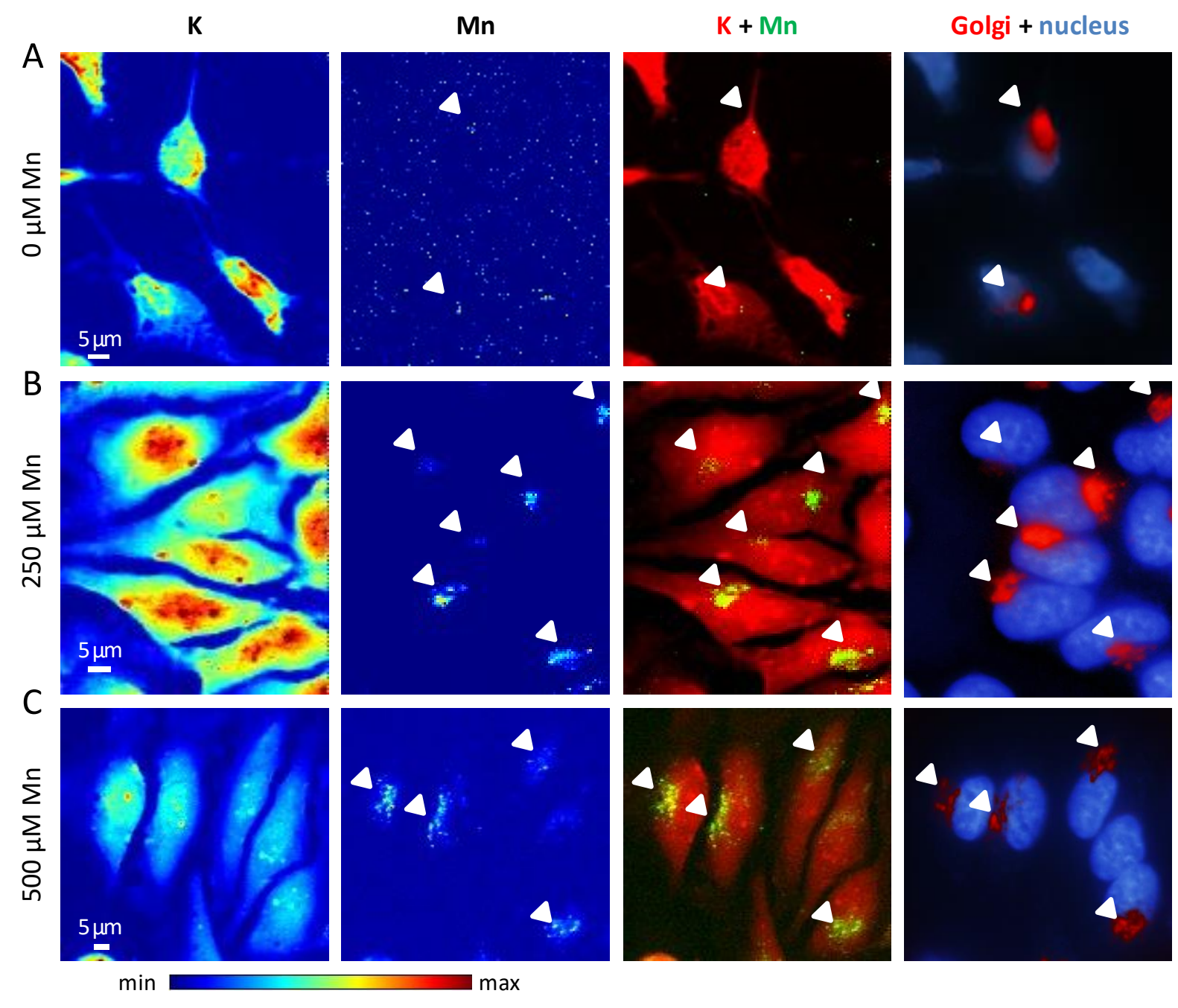

Figure 2. Representative examples of SXRF microprobe imaging of potassium $(K)$ and manganese (Mn) in not transfected HeLa cells, and comparison with the fluorescence microscopy of the Golgi apparatus and the nucleus. (A) Cells cultured without added Mn, (B) cells exposed to $250 \mu \mathrm{M} \mathrm{Mn}$, and (C) cells exposed to $500 \mu \mathrm{M} \mathrm{Mn}$. From left to right panels, $\mathrm{K}$ and $\mathrm{Mn}$ distributions in cells displayed with a color scale from minimum (blue) to maximum (red) SXRF counts, overlay images of K (red) and Mn (green), and fluorescence microscopy overlay images of nucleus staining (blue) and Golgi apparatus labeling (red). Arrows indicate Mn and Golgi apparatus co-localization.

Mn is removed from cells expressing the wild-type SLC30A10 protein but accumulates in the Golgi apparatus of SLC30A10-\$105-107 mutant. HeLa cells transfected with SLC30A10-WT-GFP protein did not contain detectable Mn, as illustrated by the lack of Mn SXRF signal in the two cells expressing the GFP-construct in Fig. 3B. Due to the correlative 
imaging approach it was possible to analyze selectively cells that were correctly transfected and not transfected from the same sample. It is interesting to observe that in the same image, transfected (green fluorescence) and not transfected cells (without green fluorescence) were both present, showing these late detectable Mn located in the Golgi apparatus (Fig. 3B). In cells transfected with SLC30A10- $\Delta$ 105-107-GFP mutant protein and exposed to $500 \mu \mathrm{M} \mathrm{MnCl}_{2}, \mathrm{Mn}$ accumulates into the Golgi apparatus (Fig. 3C), as in the case when the protein is not expressed (Fig. 3A) confirming that the mutant protein loses its ability to efflux Mn. When cells were exposed to a lower concentration of $\mathrm{MnCl}_{2}, 250 \mu \mathrm{M}$, a similar Mn distribution was found as for the $500 \mu \mathrm{M}$ exposure condition (Fig. 4). Mn is located into the Golgi apparatus when SLC30A10 protein is not expressed (Fig. 4A) and when it is mutated (Fig. 4C), whereas Mn is expelled from the cells when they express the WT-protein (Fig. 4B). Again, for $250 \mu \mathrm{M}$ exposure condition, in the WT-SLC30A10-GFP analyses, transfected cells showing GFP fluorescence had no $\mathrm{Mn}$ in the Golgi apparatus whereas in not transfected cells $\mathrm{Mn}$ is localized in the Golgi apparatus (Fig. 4B). In the case of cells exposed to a physiological concentration of $\mathrm{Mn}$, without addition in the culture medium $(0 \mu \mathrm{M})$, although the Mn content is much lower than in cells exposed to an excess of $\mathrm{Mn}, \mathrm{Mn}$ intracellular distribution follows the same trend (Fig. 5). SLC30A10-WT protein effluxes Mn from cells and Mn could not be detected (Fig. 5B). For control cells and cells exposed to the mutant protein, the quantity incorporated by the cells is very low and near of the detection limit but as previously observed, $\mathrm{Mn}$ is located within the Golgi apparatus (Fig. 5 A and C). 


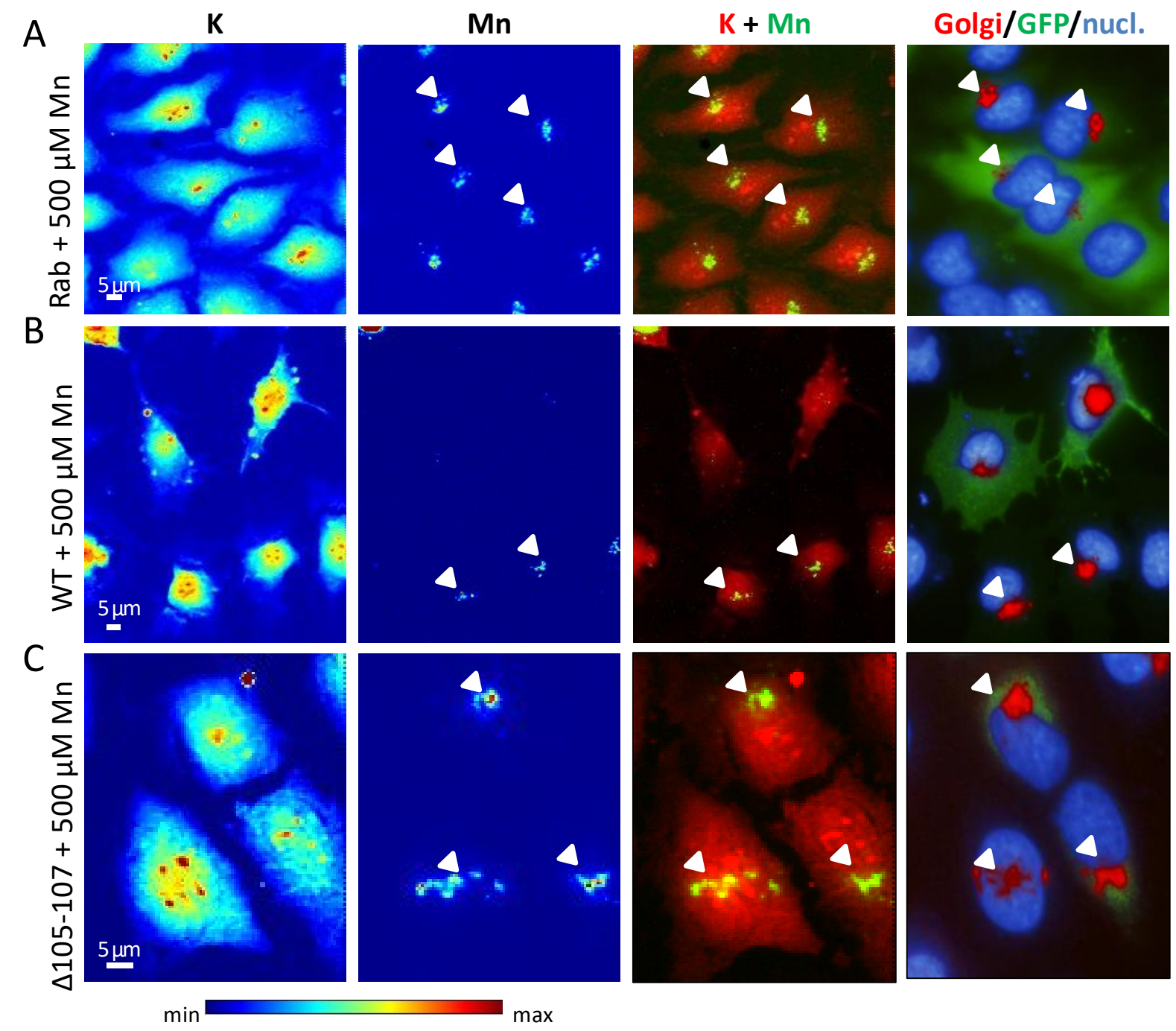

Figure 3. Representative examples of SXRF microprobe imaging of potassium $(K)$ and manganese (Mn) in HeLa cells transfected with indicated constructs exposed to $500 \mu \mathrm{M} \mathrm{Mn}$ and comparison with the fluorescence microscopy distribution of Golgi apparatus and nucleus. (A) Cells transfected with GFP-tagged Rab5 construct, (B) cells transfected with GFP-tagged SLC30A10-WT construct, and (C) cells transfected with GFP-tagged SLC30A10- $\Delta 105-107$ construct. From left to right panels, $\mathrm{K}$ and $\mathrm{Mn}$ distributions in cells displayed with a color scale from minimum (blue) to maximum (red) SXRF counts, overlay images of $\mathrm{K}$ (red) and Mn (green), fluorescence microscopy overlay images of nucleus staining (blue), Golgi apparatus labeling (red), and GFP-tagged proteins (green). Arrows indicate Mn and Golgi apparatus co- 
localization.

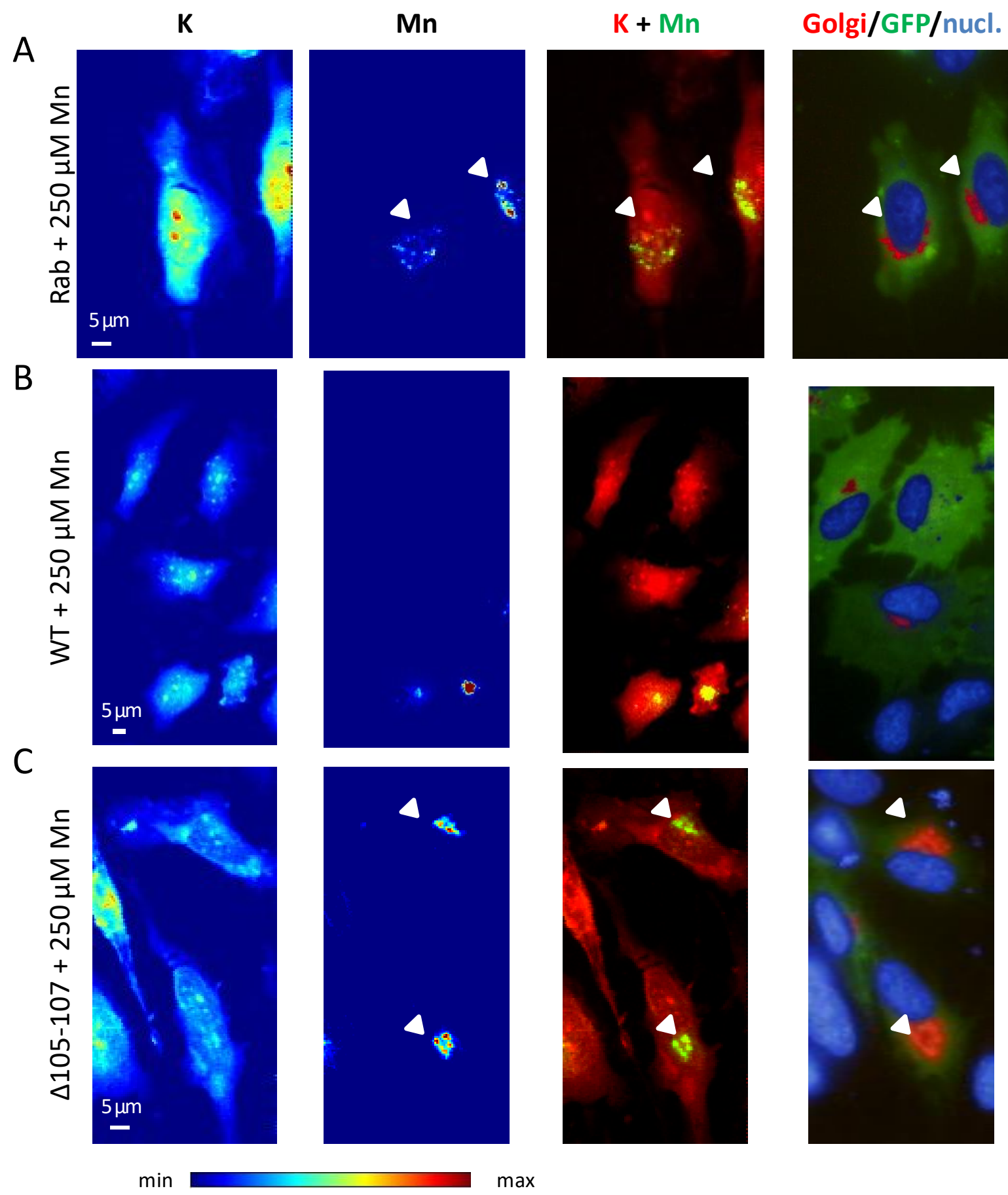

Figure 4. Representative examples of SXRF microprobe imaging of potassium $(K)$ and manganese (Mn) in HeLa cells transfected with indicated constructs exposed to $250 \mu \mathrm{M} \mathrm{Mn}$ and comparison with the fluorescence microscopy of the Golgi apparatus and the nucleus. (A) Cells transfected with GFP-tagged Rab5 construct, (B) cells transfected with GFP-tagged SLC30A10-WT construct, and (C) cells transfected with GFP-tagged SLC30A10- $\Delta 105-107$ construct. From left to right panels, $\mathrm{K}$ and $\mathrm{Mn}$ distributions in cells displayed with a color scale 
from minimum (blue) to maximum (red) SXRF counts, overlay images of $\mathrm{K}$ (red) and Mn (green), fluorescence microscopy overlay images of nucleus staining (blue), Golgi apparatus labeling (red), and GFP-tagged proteins (green). Arrows indicate Mn and Golgi apparatus colocalization.

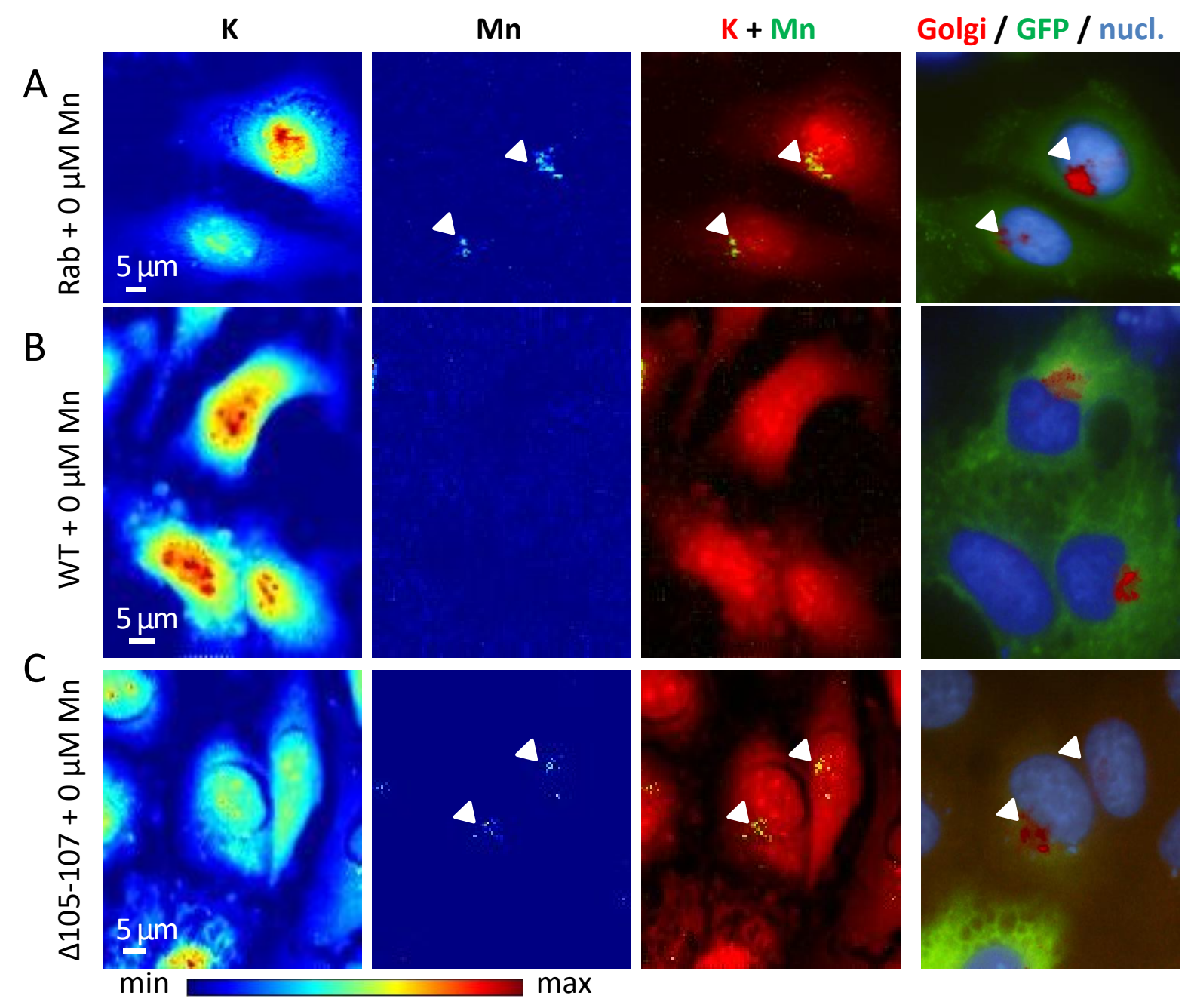

Figure 5. Representative examples of SXRF microprobe imaging of potassium $(K)$ and manganese (Mn) in HeLa cells transfected with indicated constructs exposed to physiological Mn (0 $\mu M$ added) and comparison with the fluorescence microscopy of the Golgi apparatus and the nucleus. (A) Cells transfected with GFP-tagged Rab5 construct, (B) cells transfected with GFP-tagged SLC30A10-WT construct, and (C) cells transfected with GFP-tagged SLC30A10- 1 105-107 construct. From left to right panels, $\mathrm{K}$ and Mn distributions in cells displayed with a color scale from minimum (blue) to maximum (red) SXRF counts, overlay images of K (red) and Mn (green), fluorescence microscopy overlay images of nucleus staining 
(blue), Golgi apparatus labeling (red), and GFP-tagged proteins (green). Arrows indicate Mn and Golgi apparatus co-localization.

Manganese accumulates in single vesicles of the Golgi apparatus of cells expressing the SLC30A10-D105-107 mutant. SXRF analyses were performed at high spatial resolution, with a $50 \mathrm{~nm}$ beam size, using the newly developed nanoprobe setup on ID16A beam line at ESRF $(25,26)$. For this experiment cells were imaged in their frozen hydrated state, close to their native state, without freeze drying after cryofixation. As previously, cells were transfected with SLC30A10-WT-GFP and SLC30A10- 1 105-107-GFP constructs and exposed to $500 \mu \mathrm{M}$ $\mathrm{MnCl}_{2}$ for $4 \mathrm{~h}$. Samples were cryofixed and maintained refrigerated within liquid nitrogen vapor until analyses. During SXRF analyses samples were cooled at $-153^{\circ} \mathrm{C}$ by thermal contact. SXRF imaging was performed with a $50 \mathrm{~nm}$ spatial resolution, the size of one pixel in the images being the same as the beam size, $50 \mathrm{~nm}$. SXRF analyses were performed only on fluorescent cells expressing therefore either SLC30A10-WT-GFP or the SLC30A10-A105-107-GFP mutant. Similarly, to the results previously obtained at PETRAIII P06 beamline, Mn accumulates in the perinuclear region of cells transfected with the SLC30A10- 1 105-107 mutant protein (Fig. 6 and 7) previously identified as the Golgi apparatus. In addition to the previous obtained results, the $50 \mathrm{~nm}$ resolved sub-organelle structures and evidenced that $\mathrm{Mn}$ is stored in single vesicles from $50 \mathrm{~nm}$ (or less) to $200 \mathrm{~nm}$ size. Images at $50 \mathrm{~nm}$ spatial resolution revealed the single vesicle accumulation of Mn in the Golgi apparatus. Such perinuclear Mnrich vesicles were not observed in cells expressing the wild-type SLC30A10 protein (Fig. 8). Cells transfected with the WT-protein show less number of Mn-rich structures, much spread out in the cell and of smaller size of (50-100 nm) (Fig. 8). 

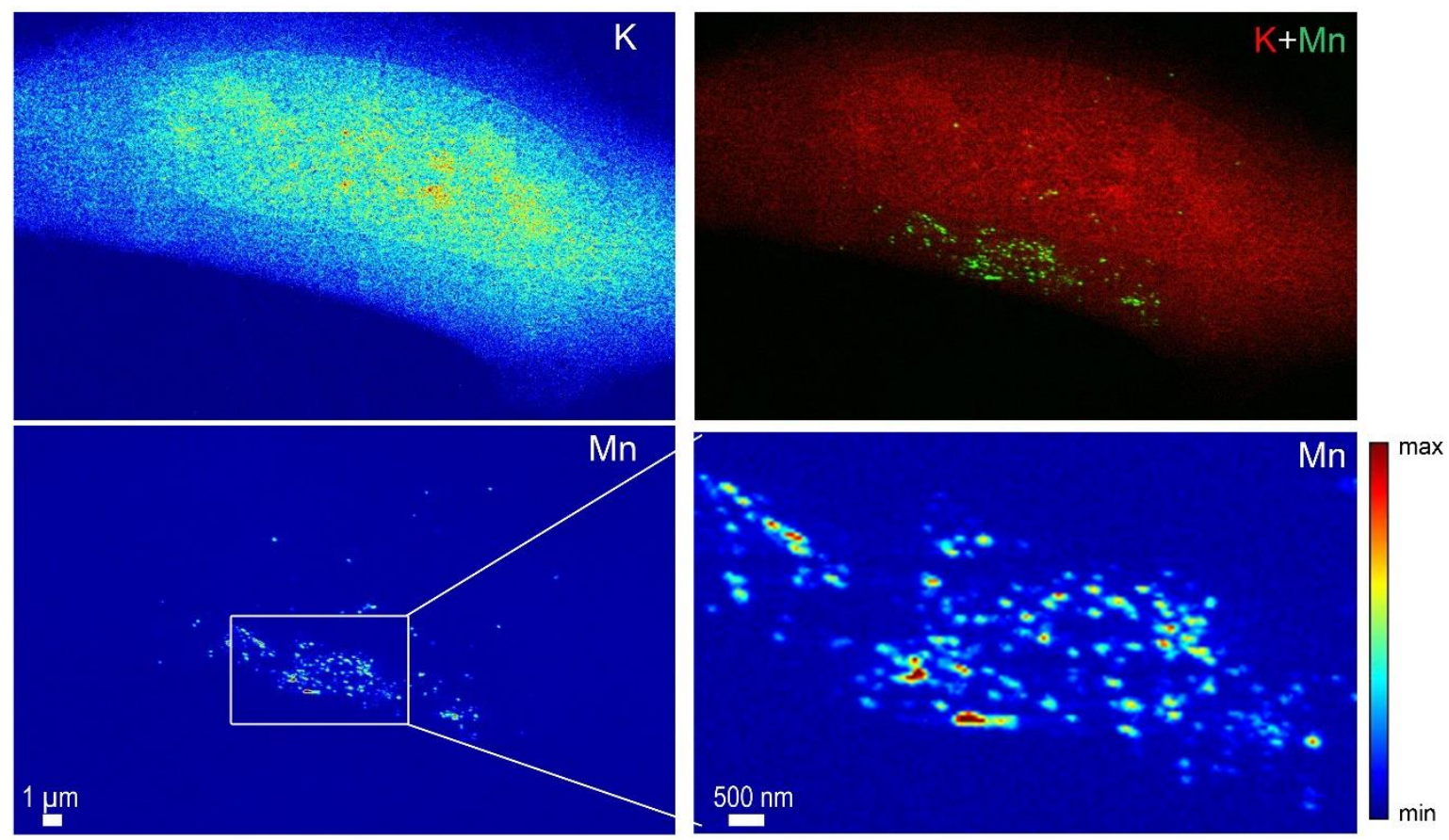

Figure 6. Potassium $(K)$ and manganese $(\mathrm{Mn})$ distributions obtained at high spatial resolution in a cell transfected with SLC30A10-4105-107-GFP and exposed to $500 \mu \mathrm{M} \mathrm{Mn.} \mathrm{A} \mathrm{zoom} \mathrm{in}$ the $\mathrm{Mn}$ rich area reveals the punctuated distribution of $\mathrm{Mn}$ in single structures as small as the beam size, $50 \mathrm{~nm}$. 


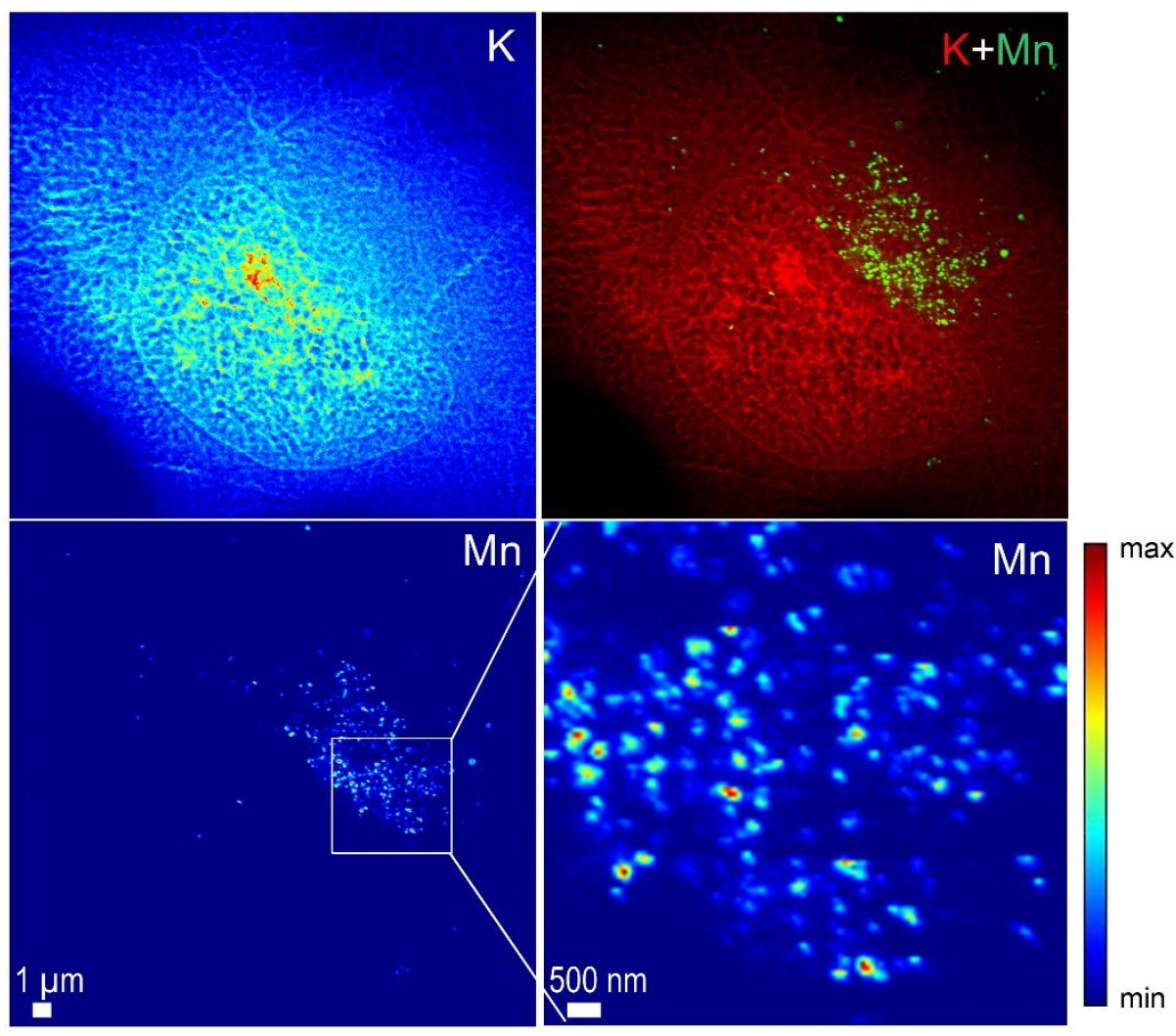

Figure 7. Potassium $(K)$ and manganese (Mn) distributions obtained at high spatial resolution in a cell transfected with SLC30A10-4105-107-GFP and exposed to $500 \mu \mathrm{M} \mathrm{Mn}$. A zoom in the $\mathrm{Mn}$ rich area reveals the punctuated distribution of $\mathrm{Mn}$ in single structures as small as the beam size, $50 \mathrm{~nm}$. 

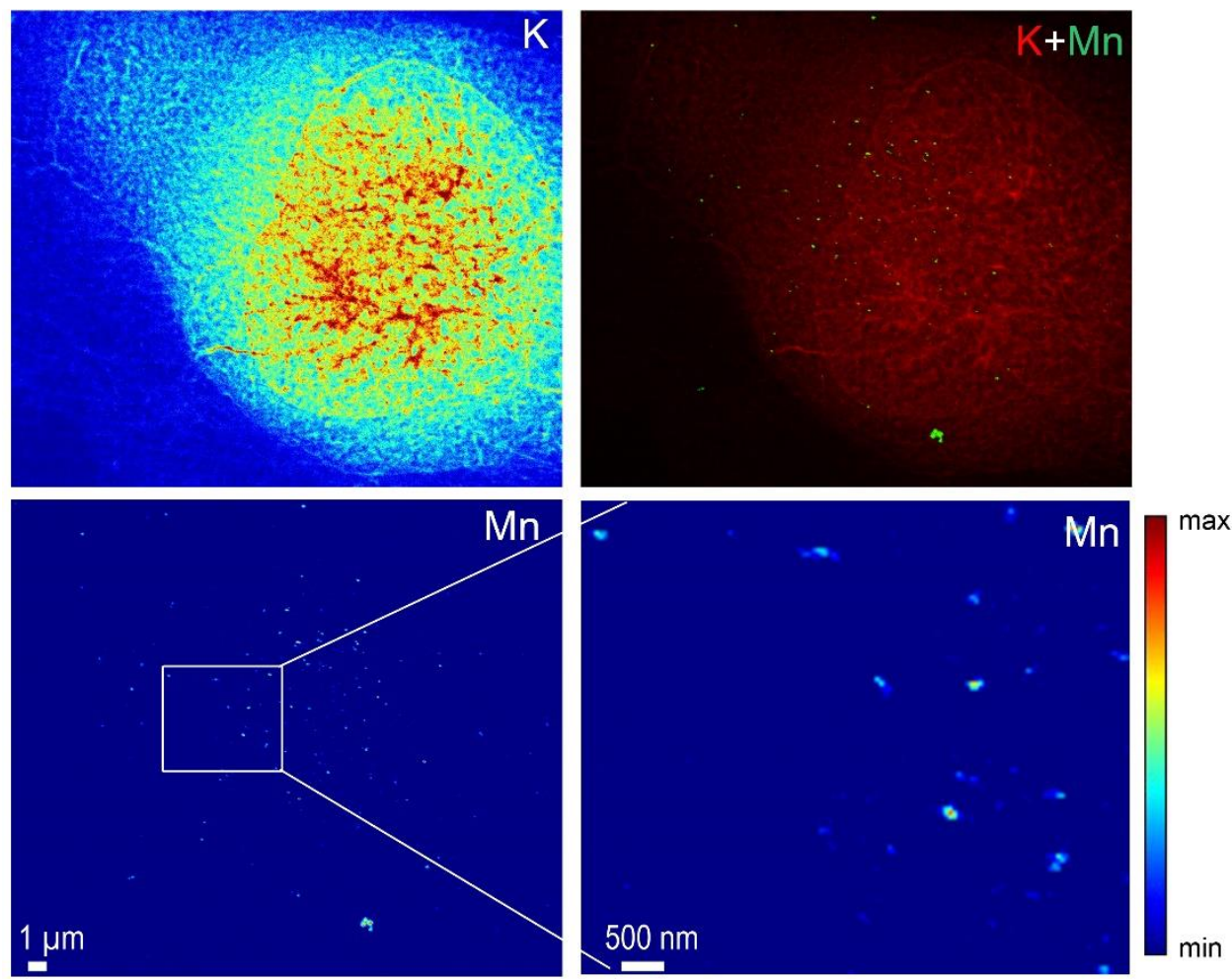

Figure 8. Potassium $(K)$ and manganese (Mn) distributions obtained at high spatial resolution in a cell transfected with SLC30A10-WT-GFP and exposed to $500 \mu \mathrm{MMn}$. In this case the number of Mn hot spots is lower in the cells expressing the mutant protein and is not restricted to the perinuclear area of the cell.

\section{DISCUSSION}

$\mathrm{Mn}$ is an essential trace metal present in human tissues at the $0.1-1 \mu \mathrm{g} \cdot \mathrm{g}^{-1}$ wet weight range concentration (1). Although many analytical methods are suitable to detect and quantify Mn in bulk specimen at this concentration range, the imaging of Mn distribution in a single cell still remains a challenging task due to its low content of about in total $10^{-16} \mathrm{~g}$ in a single cell, and less in subcellular compartments. Therefore indications of $\mathrm{Mn}$ intracellular distribution are mostly and indirectly derived from the localization of Mn-transport and Mn-binding proteins in human cells, giving a helpful but incomplete picture of Mn distribution (3). The identification of $\mathrm{Mn}$ intracellular distribution is required to describe modifications of Mn trafficking in human cells related to pathological processes. In this study we applied SXRF micro- and nano-imaging to map Mn distribution in HeLa cells expressing or not the SLC30A10 Mn transporter protein or its $\Delta 105-107$ mutation. 
Mn accumulates in the Golgi apparatus of cells not expressing SLC30A10. HeLa cells accumulate $\mathrm{Mn}$ in the Golgi apparatus as evidenced by SXRF and organelle epifluorescence correlative imaging (Fig. 2). Similarly, in HeLa cells mock-transfected with Rab5-GFP protein, $\mathrm{Mn}$ is mainly located in the Golgi apparatus with or without Mn exposure (Fig. 3A, 4A and 5A). The localization of $\mathrm{Mn}$ in the Golgi apparatus of HeLa cells is in good agreement with our previous reports of Mn distribution in PC12 cells $(21,27,28)$. PC12 cells are derived from a rat pheochromocytoma. In both cell lines, HeLa and PC12, we have found that the main intracellular compartment of Mn accumulation was the Golgi apparatus. It is noteworthy that $\mathrm{Mn}$ is mainly located into the Golgi apparatus also at physiological levels of exposure, without adding Mn to the cell culture medium, for both cell lines (Fig. 5) (21, 27).

The subcellular distribution of $\mathrm{Mn}$ has long been difficult to assess due to limitations in analytical tools. It is only recently that the identification of the Golgi apparatus as one of the main organelle of Mn accumulation could be clearly evidenced first in PC12 cells and now in HeLa. This identification was possible thanks to the development of a correlative microscopy methodology based on direct Mn imaging using SXRF and fluorescent organelle labelling in whole cells $(20,21)$. The first organelles to be identified as the main potential sites of $\mathrm{Mn}$ accumulation in cells such were the mitochondria (29) and the nucleus $(29,30)$. In brain tissue sections of animals intoxicated with $\mathrm{Mn}$, electron spectroscopy imaging coupled to transmission electron microscopy unambiguously revealed the presence of $\mathrm{Mn}$ in the mitochondria, the cytoplasm and the nucleus of neurons and astrocytes (29). In relative proportion, Mn was detected in higher amount first in the nucleus, then in the cytoplasm and in the mitochondria. This pioneer work enabled to detect the presence of $\mathrm{Mn}$ in the nucleus, more specifically in the heterochromatin regions of both neurons and astrocytes and in the nucleolus of neurons. However, in this study it is very likely that only Mn tightly bound to biomolecules could be detected since samples were chemically fixed with aldehydes and embedded in resins. Sample preparation protocols for electron microscopy based on chemical fixation with paraformaldehyde and/or glutaraldehyde and dehydration with organic solvents (acetone, propylene oxide) produces a permeabilization of the cell membrane and are known to remove large amounts of intracellular elements (20, 23, 31-34). As reported by the authors about 50\% of total Mn was removed during sample preparation of the brain tissue sections (29). It is very likely that most of these $50 \%$ of lost Mn were present in the cytoplasm in a more diffusible state than in the mitochondria or the nucleus, as also observed for other elements such as $\mathrm{Zn}(20,33)$. Therefore, although electron microscopy analysis was very useful to evidence the presence of 
$\mathrm{Mn}$ in mitochondria and nuclei it was unable to detect Mn in the Golgi apparatus since this pool of $\mathrm{Mn}$ is more diffusible and was probably lost during sample preparation. Another important study of Mn subcellular localization has been performed on cultured brain cells by using a radioactive $\mathrm{Mn}$ tracer $\left({ }^{54} \mathrm{Mn}\right)$ and centrifugation to separate cellular fractions: nuclei, cytoplasm, mitochondria, and microsomes (pellet) (30). Four brain cell lines were investigated, blood-brain barrier endothelial RBE4 cells, blood-cerebrospinal fluid barrier choroidal epithelial Z310 cells, mesencephalic dopaminergic neuronal N27 cells, and pheochromocytoma dopaminergic PC12 cells. The cytoplasmic versus nuclear Mn content were highly variable among the 4 different cell lines under study with a greater content in the nucleus of endothelial RBE4 and Z310 epithelial cells, and a greater content in the cytoplasm of N27 and PC12 dopaminergic cells. In PC12 cells exposed to $100 \mu \mathrm{M} \mathrm{MnCl}_{2}, 69 \%$ of $\mathrm{Mn}$ was detected in the cytoplasm and $27 \%$ in the nucleus. This result seems close to the one we reported in a previous study (27) showing that in PC12 cells exposed to $100 \mu \mathrm{M} \mathrm{MnCl}_{2}, 20 \%$ of $\mathrm{Mn}$ was in the nucleus, and $80 \%$ outside the nucleus which included the cytoplasmic and Golgi apparatus areas. Moreover, in a latter study (21) the correlative SXRF-organelle labelling approach enabled to identify the Golgi apparatus as the main organelle of Mn accumulation in PC12 cells.

We can conclude that Mn localization in the Golgi apparatus of human HeLa and rat PC12 cells has been clearly identified after physiological and toxicological exposure conditions. A similar perinuclear accumulation is observed in other cell systems. Recently, SXRF imaging of mouse pancreatic beta cells, mouse primary dopaminergic and hippocampal neurons, have also evidenced the perinuclear localization of Mn which might potentially be located within the Golgi apparatus although in these studies a correlative microscopy approach was not implemented (35-38). For instance (35) reported that in the MIN6 mouse pancreatic beta cell line, Mn was prevalent in the cytoplasm and localized primarily in a perinuclear region, and hypothesized that this localization could possibly correspond to the Golgi apparatus. In mouse primary dopaminergic neurons a cytoplasmic perinuclear localization was observed after $\mathrm{Mn}$ exposure using SXRF imaging $(36,38)$. A perinuclear distribution of Mn was also reported in mouse hippocampal neurons and in neuron-like N2a cells exposed to Mn (37). A second site of Mn accumulation in cells is the nucleus $(27,29,30,35)$ and the relative proportion of $\mathrm{Mn}$ in the Golgi apparatus versus the nucleus might depend on the cellular type (30) and on the amplitude of Mn exposure since Mn will preferentially accumulate in the Golgi apparatus for high exposure conditions (21). 
Why does Mn accumulate in the Golgi apparatus of HeLa cells? In human cells, SPCA1 (secretory pathway $\mathrm{Ca}^{2+}$-ATPase isoform 1) is involved in the detoxification of $\mathrm{Mn}$ (18). SPCA1 is located on the Golgi membrane and can transport $\mathrm{Ca}^{2+}$ and $\mathrm{Mn}^{2+}$ ions into the Golgi lumen. By this mechanism excess $\mathrm{Ca}^{2+}$ or $\mathrm{Mn}^{2+}$ can be removed from the cytosol and exported through the secretory pathway. Immunochemistry experiments reported that endogenous SPCA1 is expressed in HeLa cells where it is responsible for $\mathrm{Ca}^{2+}$ uptake in a sub-fraction of the Golgi apparatus (39). In HeLa cells, SPCA1 is located mostly on the lateral rims of Golgi stacks, in tubular non compact zones that interconnect different Golgi stacks, and within tubular parts of the trans Golgi network (TGN) and is excluded from the cores of the Golgi cisternae (40). In liver cells, SPCA1 is co-localized with the TGN protein TGN38 and is involved in Mn detoxification (41). A striking observation is that Mn distribution at the sub-Golgi level obtained by nano-SXRF looks like the one described for SPCA1 distribution since Mn is present mostly in vesicular rather than in core cisternae-like structures (Fig. 6 and 7). It is therefore reasonable to presume that SPCA1 could transport and store Mn into the Golgi vesicles of HeLa cells exposed to excess Mn.

Mn is efficiently expelled from cells expressing SLC30A10. When HeLa cells are transfected with the WT-SLC30A10 protein they do not accumulate Mn into the Golgi apparatus anymore and maintain low levels of intracellular Mn (Fig. 3-5 and 8). As revealed by nano-SXRF imaging, WT-SLC30A10 cells contain only a few small structures rich in Mn, of maximum 100 $\mathrm{nm}$ size, even after $500 \mu \mathrm{M}$ Mn exposure (Fig. 8). These Mn-rich structures seems too small to be mitochondria, which are usually in the 0.75 to $1 \mu \mathrm{m}$ range size. Mn-rich structures are found in the cytoplasmic and nuclear areas, although in this latter case it cannot be excluded, due to the 2D nature of SXRF imaging, that Mn-rich structures are only present in the cytoplasmic region, below or above the nucleus. The nature of the Mn-rich structures is still elusive and further analysis is required to identify which biological structure they are potentially involving. From SXRF imaging it can be concluded that when WT-SLC30A10 is expressed Mn is very efficiently excreted outside the cell and also that $\mathrm{Mn}$ is not present anymore in the Golgi apparatus. This observation suggest that the most plausible mechanism for Mn excretion is a rapid efflux through SLC30A10 transport outside the cell immediately after its uptake. This assumption is based first on the fact that even for a relatively high Mn exposure $(500 \mu \mathrm{M})$ no $\mathrm{Mn}$ is observed in the Golgi apparatus indicating that Mn does not seem to transit through the vesicular pathway to be later removed from the cell. Second, the protein SLC30A10 is 
expressed mainly in the plasma membrane which is consistent with a direct efflux mechanisms. However, the over-expression of SLC30A10 in our cell transfection model might not fully reflect the normal conditions of SLC30A10 expression and might result in an increased efflux efficiency that could mask some other cellular pathways, Mn being very efficiently removed from the cells. It is interesting to note that in cells that do not endogenously expressed SLC30A10 such as HeLa cells $(11,13,15)$ and PC12 cells (42), Mn accumulates in the Golgi apparatus probably for its detoxification through the vesicular pathway.

Mn accumulates in the Golgi apparatus of mutants SLC30A10-D105-107. HeLa cells transfected with the mutant SLC30A10- $\Delta 105-107$ protein accumulates Mn compared to the wild-type expressing system (Fig. 1). Similar results were recently reported showing that HeLa cells transfected with SLC30A10 mutant proteins accumulated Mn compared to the wild-type (11). In our study we found that the excess of Mn is stored in the Golgi apparatus as evidenced by SXRF imaging. Moreover, nano-SXRF imaging revealed the sub-organelle distribution of $\mathrm{Mn}$ in form of punctuated structures within the Golgi apparatus suggesting its accumulation in Golgi vesicles rather than in the Golgi cisternae. This accumulation is proportional to the exposure concentration. Similarly to the control HeLa cells that do not express endogenously SLC30A10, transfection with SLC30A10-4105-107 mutant results in the loss of Mn efflux. Mn accumulates into single vesicles of the Golgi apparatus potentially through a mechanisms involving SPCA1 pumping excess Mn from the cytosol to the Golgi lumen (Fig. 9). 
A) SLC30A10

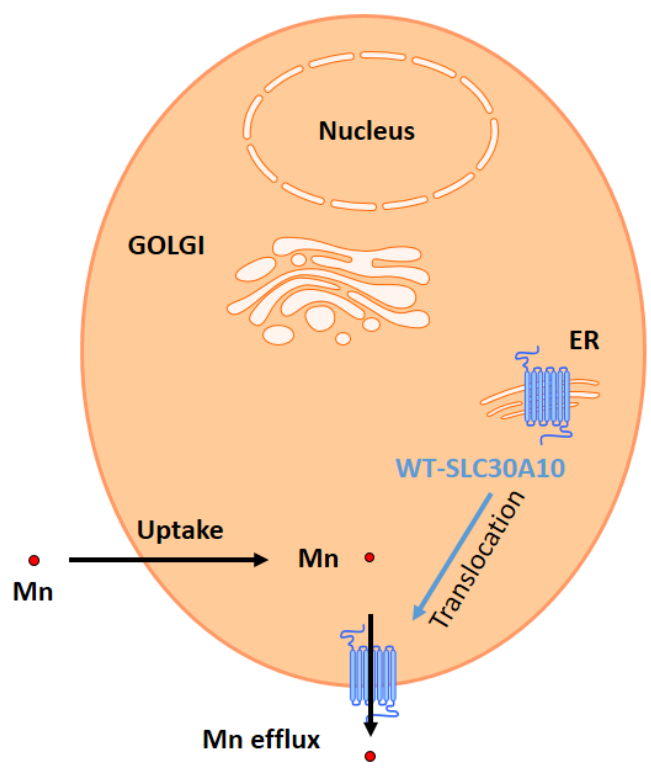

B) SLC30A10 MUTANT

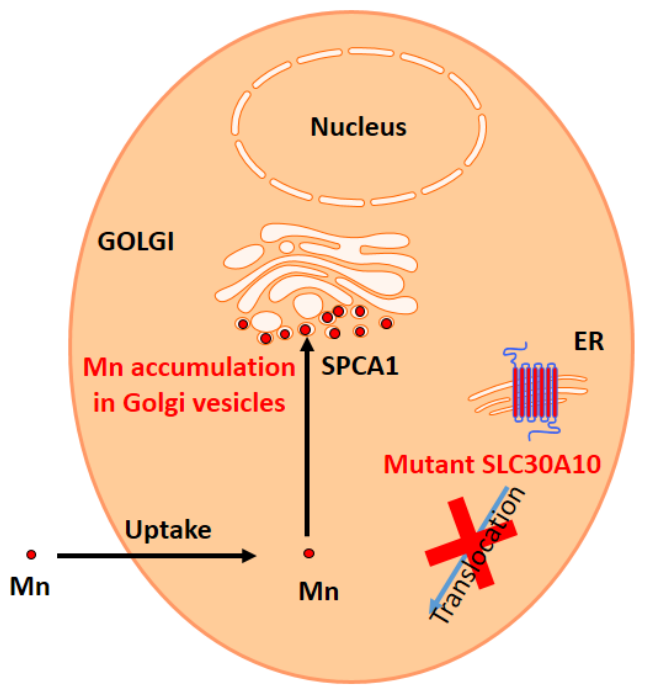

Figure 9. (A) In cells expressing SLC30A10-WT Mn is immediately excreted by the SLC30A10 protein expressed at the plasma membrane. (B) In cells expressing the mutant, the SLC30A10- $\Delta 105-107$ protein is blocked in the ER and cannot be translocated to the plasma membrane resulting in Mn uptake in the cytoplasm. Mn is pumped from the cytoplasm into the Golgi vesicles by SPCA1 resulting in Mn accumulation in Golgi vesicles.

A second mechanism of Mn detoxification might also involve SLC30A10. This second mechanism presented below is more hypothetical and mainly based on indirect evidence. First, it is surprising to observe that in SLC30A10- $105-107$ mutant Mn stays in the Golgi apparatus as it could be expected that Mn would transit in through the Golgi apparatus before being excreted via the secretory pathway. In this case Mn distribution would be more diffuse than the one observed and not almost exclusively restricted to the Golgi vesicles in SLC30A10- $\Delta 105$ 107 mutant. A potential explanation is that SLC30A10 could be required to transport Mn from the Golgi vesicles to other organelles in order to be expelled. Immunohistochemical staining has indicated the localization of wild type SLC30A10 not only at the plasma membrane but also throughout the secretory pathway, including the Golgi system and endosomes (6). This mechanism would be impeded by the disease causing mutations blocking SLC30A10 in the ER and therefore blocking $\mathrm{Mn}$ in the Golgi vesicles. This is also indirectly suggested by the $\mathrm{Mn}$ accumulation in the Golgi apparatus of HeLa and PC12 cells that do not express endogenous SLC30A10. 
In conclusion, we propose the following mechanism for Mn toxicity in SLC30A10 mutants (Fig. 9). In cells expressing the functional SLC30A10 protein, Mn is efficiently expelled outside the cell, probably immediately after uptake since $\mathrm{Mn}$ is detected only in very small amount even after high exposure conditions. The pathological mutant proteins SLC30A10- $\Delta 105-107$ are blocked in the ER impeding the translocation to the plasma membrane and Mn efflux. Mn excess is stored within Golgi vesicles by SPCA1 transport. At high concentrations Mn becomes toxic possibly because it disturbs the Golgi functions where it greatly accumulates in the absence of functional SLC30A10. Altered vesicular trafficking could be at the origin of the toxicity of the disease causing mutations of SLC30A10. Next it would be interesting to investigate whether Mn causes defects in Golgi vesicular trafficking and consequently on neurotransmitters or endocrine excretion.

Several disease-causing mutations in SLC30A10 block the capability of the transporter to traffic to the cell surface. In this paper, we show that SLC30A10- $105-107$ lacks transport activity. However, whether the other mutations that block SLC30A10 trafficking also inhibit manganese efflux activity is not yet known. If these mutated form retain transport activity, small molecules that target them to the plasma membrane may be therapeutically effective. In the future, it will be important to expand this work into more disease-relevant systems. In particular, it will be interesting to determine whether a similar pattern of Mn accumulation is evident in primary basal ganglia neurons of wild-type mice exposed to elevated manganese by drinking water, and in SLC30A10 knockout mice, which are now available. Elucidation of similar changes in mouse models will suggest that Mn induced changes in protein trafficking may underlie neurological deficits observed in human patients exposed to elevated Mn.

\section{METHODS}

Cell culture. HeLa cells were grown in minimum essential medium (MEM) supplemented with $10 \%$ fetal bovine serum and $100 \mathrm{U} / \mathrm{mL}$ penicillin-streptomycin at $37^{\circ} \mathrm{C}$ in a water-saturated atmosphere containing 5\% $\mathrm{CO}_{2}$. All cell culture products were purchased from Sigma.

\section{Plasmid constructions.}


GFP-tagged Rab5 or SLC30A10-WT constructs were described previously (43). Deletions were introduced into the SLC30A10WT construct by using the loop-in modification of the QuickChange protocol as described previously (44).

Viability assays. Assessment of cell viability using the methylthiazolyldiphenyl-tetrazolium bromide (MTT) assay and measurement of intracellular metals, using inductively-coupled plasma mass spectrometry were performed as described previously (11).

Cell culture for SXRF imaging. For synchrotron X-ray fluorescence analyses cells were cultured directly on sample holders specifically adapted to each synchrotron beamline. For P06 microprobe beamline at PETRAIII synchrotron DESY, we used a custom made plastic (PEEK) sample holder with a square hole of $5 \mathrm{~mm}$ side covered with a $2 \mu \mathrm{m}$ thick ultrapure polycarbonate foil as previously described $(23,24,45,46)$. For ID16A nanoprobe experiments at ESRF we used as sample holder $\mathrm{Si}_{3} \mathrm{~N}_{4}$ membranes of $1.5 \mathrm{~mm}$ side length and $500 \mathrm{~nm}$ thickness (Silson) as recently adapted for high resolution trace metal imaging (26). To facilitate cell adhesion both kinds of sample holders, polycarbonate mounted on PEEK and $\mathrm{Si}_{3} \mathrm{~N}_{4}$ membranes, were treated with $2 \%$ gelatin gel (Sigma) for 15 minutes at $37^{\circ} \mathrm{C}$ and gelatin was washed 3 times with sterile ultrapure water (OPTIMA, Thermo Fisher Scientific). Cells were seeded directly on the treated sample holders, polycarbonate foils or $\mathrm{Si}_{3} \mathrm{~N}_{4}$ membranes, at low density $\left(10000\right.$ cells $\left.\mathrm{cm}^{-2}\right)$. Cells cultured on the samples holders were transfected with the constructs of interest and then transduced for organelle labelling to enable correlative SXRF and organelle fluorescence microscopy (20). Transfection was achieved $24 \mathrm{~h}$ after seeding and transduction $48 \mathrm{~h}$ after transfection. One day after transduction cells were exposed to $\mathrm{Mn}$ for $4 \mathrm{~h}$. $\mathrm{MnCl}_{2}$ (Sigma) was freshly prepared at 250 or $500 \mu \mathrm{M}$ for each experiment. Afterwards, and prior to fluorescence observation, Hoechst (33342 Sigma) staining was added at $10 \mu \mathrm{g} \cdot \mathrm{mL}^{-1}$ into culture medium for 10 minutes at $37^{\circ} \mathrm{C}$.

Cell transfection and organelle labelling. HeLa cells were routinely transfected $24 \mathrm{~h}$ after seeding using JetPEI ${ }^{\circledR}$ transfection reagent (Polyplus transfection) according to the manufacturer's protocol. For transfection, GFP constructions of SLC30A10 protein and Rab5 were elaborated as explained in a previous section. Forty-eight hours after transfection, cells were transduced with CellLight ${ }^{\mathrm{TM}}$ Golgi-RFP (C10593 Molecular probes) following the 
provided protocol. CellLight ${ }^{\circledR}$ reagent use BacMam technology to transduce cells with a human Golgi resident enzyme (N-acetylgalactosaminyltransferase) fused to RFP. Cells transfected with one of the three GFP constructions and then transduced with a CellLight ${ }^{\circledR}$ reagent kit, were exposed to 250 or $500 \mu \mathrm{M} \mathrm{MnCl}_{2}$ for $4 \mathrm{~h}$ and then incubated with the blue nuclear dye Hoechst 33342 (Sigma). After transfection, transduction, Mn exposition and nuclear staining, cells fluorescence images of living cells were acquired using an epifluorescence microscope (BX51, Olympus, Tokyo, Japan). For each condition, control, SLC30A10-WT and SLC30A10$\Delta 105-107$, images of GFP-transfected cells were recorded, those exhibiting green fluorescence were considered for further analysis.

Sample processing for SXRF imaging. After acquiring epifluorescence images, samples were processed for further SXRF analyses. The first step consists in a cryofixation by rapid immersion of the sample into a cryogenic fluid. For this purpose, samples were cryofixed by plunging into liquid isopentane $\left(-160^{\circ} \mathrm{C}\right)$ cooled with liquid nitrogen as previously described (23). At the DESY P06 beamline analyses were performed in air at room temperature requiring a freeze-drying step performed at low temperature $\left(-85^{\circ} \mathrm{C}\right)$ and under vacuum (23). This protocol preserves the cellular morphology and avoids any chemical modification of elements into the cells (23). At ESRF ID16A beamline, the analyses were carried out with a cryogenic sample stage. Samples were not freeze dried, and after cryofixation samples were kept in liquid nitrogen vapors until the experiment.

SXRF imaging. Synchrotron experiments were conducted at two different facilities. First at P06 hard X-ray micro-probe beamline at PETRAIII synchrotron DESY (Deutsches ElektronenSynchrotron) in Hambourg, Germany (22) and later at ID16A nano-imaging beamline at ESRF (European Synchrotron Radiation Facility) in Grenoble, France (25). At DESY micro-SXRF was performed in air at room temperature. The beam energy was set to $10.0 \mathrm{keV}$ and the provided flux was $10^{10} \mathrm{ph} \cdot \mathrm{s}^{-1}$. The samples were mounted on a sample holder which allows nanometer range displacements. The beam was focused to $700 \mathrm{~nm}$ (horizontal) and $800 \mathrm{~nm}$ (vertical). Samples were scanned in the x-ray focal plane with $500 \mathrm{~nm}$ step and a dwell time of $300 \mathrm{~ms}$. Fluorescence signal was collected using a Maia detector placed in backscatter geometry. The SXRF signal was deconvoluted and normalized to the incident flux using GeoPIXE (47). At ESRF nano-SXRF was performed using a cryo-stage cooled by thermal contact with liquid nitrogen $\left(-196^{\circ} \mathrm{C}\right)$. Beam energy was set to $17.05 \mathrm{keV}$ and the provided flux was $1.7 \cdot 10^{11} \mathrm{ph} \cdot \mathrm{s}^{-1}$. The beam was focused at $50 \mathrm{~nm}$ (horizontal) and $58 \mathrm{~nm}$ (vertical) size. Images were performed by scanning the sample with $50 \mathrm{~nm}$ step and $50 \mathrm{~ms}$ dwell time. Analyses 
were performed under high vacuum and the fluorescence signal was collected with a silicon drift diode detector. Elemental maps were normalized using PyMCA software (48).

Statistical analysis. For Mn determination using ICP-MS, analysis from three independent experiments were performed (Figure 1D, mean $\pm \mathrm{SE} ; * \mathrm{p}<0.05$ between $\mathrm{WT}$ and other groups using one way ANOVA and Tukey Kramer post hoc test). For cell viability assays (Figure 1E), viability at $0 \mathrm{mM} \mathrm{Mn}$ was set to 100 and used to calculate the percent viability after $\mathrm{Mn}$ treatment (mean $\pm \mathrm{SE} ; \mathrm{n}=3 ; * \mathrm{p}<0.05$ for the difference between the viability of SLC30A10WT-expressing cells and other groups at indicated concentrations using two-way ANOVA and Tukey Kramer post hoc test).

\section{AUTHOR INFORMATION}

\section{Corresponding Authors}

Asuncion Carmona, acarmona@cenbg.in2p3.fr and Richard Ortega, ortega@cenbg.in2p3.fr

\section{Author Contributions}

A.C., S.M. and R.O. designed research. C.E.Z. and S.M. designed plasmids, and were involved in viability assays, immunofluorescence and ICP-MS experiments. A.C. was involved in sample preparation for SXRF experiments. A.C., S.R., F.P., J.G., K.M.S. and R.O. were involved in SXRF experiments at PETRA. A.C., S.R., M.S., P.C., and R.O. were involved in SXRF experiments at ESRF. AC, K.M.S., J.G., M.S., P.C. and R.O. were involved in SXRF data analysis. AC, S.M. and R.O. wrote the manuscript. All authors critically revised the manuscript.

\section{Funding}

This work was funded by the CNRS-IN2P3 Master Project IFI (Imagerie par Faisceau d'Ions). This work was also supported by NIH grants R01-ES024812 (S.M.) and NIH/NIEHS predoctoral fellowship 1F31-ES027317 (C.E.Z.).

\section{Notes}

The authors declare no competing financial interest. 


\section{ACKNOWLEDGEMENTS}

Parts of this research were carried out at PETRAIII at DESY, a member of the Helmholtz Association (HGF). We would like to thank staff from P06 beamline for assistance. Part of the experiments were also performed on beamline ID16A at the European Synchrotron Radiation Facility (ESRF), Grenoble, France. We are grateful to ID16A staff at the ESRF for providing assistance in using the beamline.

\section{REFERENCES}

(1) Saric, M. and Lucchini, R. Manganese. Handbook on the Toxicology of Metals (Third Edition), eds Nordberg G.F., Fowler B.A., Nordberg M., Friberg L.T., pp 645-674 (Academic Press, Elsevier, London, 2007).

(2) Avila, D.S., Puntel R.L. and Aschner M. (2013) Manganese in health and disease. Met. Ions Life Sci. 13, 199-227.

(3) Horning, K.J., Caito, S.W., Tipps, K.G., Bowman, A.B. and Aschner, M. (2015) Manganese is essential for neuronal health. Annu. Rev. Nutr. 35, 71-108.

(4) Aschner, M., Erikson, K.M., Hernández, E.H. and Tjalkens, R. (2009) Manganese and its role in Parkinson's disease: from transport to neuropathology. NeuroMolecular Med. 11, $252-266$.

(5) Lucchini, R.G., Guazzetti, S., Zoni, S., Donna, F., Peter, S., Zacco, A., Salmistraro, M., Bontempi, E., Zimmerman, N.J. and Smith, D.R. (2012) Tremor, olfactory and motor changes in Italian adolescents exposed to historical ferro-manganese emission.

Neurotoxicology 33, 687-696.

(6) Quadri, M., Federico, A., Zhao, T., Breedveld, G.J., Battisti, C., Delnooz, C., Severijnen, L.A., Di Toro Mammarella, L., Mignarri, A., Monti, L., Sanna, A., Lu, P., Punzo, F., Cossu, G., Willemsen, R., Rasi, F., Oostra, B.A., van de Warrenburg, B.P. and Bonifati, V. 
(2012) Mutations in SLC30A10 cause parkinsonism and dystonia with hypermanganesemia, polycythemia, and chronic liver disease. Am. J .Hum. Genet. 90, 467-477.

(7) Tuschl, K., Clayton, P.T., Gospe, S.M. and Mills, P.B. Dystonia/Parkinsonism, Hypermanganesemia, Polycythemia, and Chronic Liver Disease. GeneReviews ${ }^{\circledR}$ [Internet], eds Adam M.P., Ardinger H.H., Pagon R.A., et al. (University of Washington, Seattle (WA), 2012) Available from: http://www.ncbi.nlm.nih.gov/books/NBK100241/.

(8) Tuschl, K., Clayton, P.T., Gospe Jr, S.M., Gulab, S., Ibrahim, S., Singhi, P., Aulakh, R., Ribeiro, R.T., Barsottini, O.G., Zaki, M.S., Del Rosario, M.L., Dyack, S., Price, V., Rideout, A., Gordon, K., Wevers, R.A., Chong, W.K. and Mills, P.B. (2012) Syndrome of hepatic cirrhosis, dystonia, polycythemia, and hypermanganesemia caused by mutations in SLC30A10, a manganese transporter in man. Am. J. Hum. Genet. 90, 457-466.

(9) Jenkitkasemwong, S., Akinyode, A., Paulus, E., Weiskirchen, R., Hojyo, S., Fukada, T., Giraldo, G., Schrier, J., Garcia, A., Janus, C., Giasson, B. and Knutson, M.D. (2018) SLC39A14 deficiency alters manganese homeostasis and excretion resulting in brain manganese accumulation and motor deficits in mice. Proc. Natl. Acad. Sci. U. S. A. 115, E1769-E1778.

(10) Mukhopadhyay, S. (2018) Familial manganese-induced neurotoxicity due to mutations in SLC30A10 or SLC39A14. Neurotoxicology 64, 278-283.

(11) Leyva-Illades, D., Chen, P., Zogzas, C.E., Hutchens, S., Mercado, J.M., Swaim, C.D., Morrisett, R.A., Bowman, A.B., Aschner, M. and Mukhopadhyay, (2014) S. SLC30A10 is a cell surface-localized manganese efflux transporter, and parkinsonism-causing mutations block its intracellular trafficking and efflux activity. J. Neurosci. 34, 14079-14095.

(12) Chen, P., Bowman, A.B., Mukhopadhyay, S. and Aschner, M. (2015) SLC30A10: a novel manganese transporter. Worm 4, e1042648.

(13) Zogzas, C.E., Aschner, M. and Mukhopadhyay, S. (2016) Structural elements in the transmembrane and cytoplasmic domains of the metal transporter SLC30A10 are required for its manganese efflux activity. J. Biol. Chem. 291, 15940-15957.

(14) Hutchens, S., Liu, C., Jursa, T., Shawlot, W., Chaffee, B.K., Yin, W., Gore, A.C., Aschner, M., Smith, D.R. and Mukhopadhyay, S. (2017) Deficiency in the manganese efflux 
transporter SLC30A10 induces severe hypothyroidism in mice. J. Biol. Chem. 292, 97609773.

(15) Xia, Z., Wei, J., Li, Y., Wang, J., Li, W., Wang, K., Hong, X., Zhao, L., Chen, C., Min, J. and Wang, F. (2017) Zebrafish slc30a10 deficiency revealed a novel compensatory mechanism of Atp2c1 in maintaining manganese homeostasis. PLOS Genet. 13, e1006892.

(16) Liu, C., Hutchens, S., Jursa, T., Shawlot, W., Polishchuk, E.V., Polishchuk, R.S., Dray, B.K., Gore, A.C., Aschner, M., Smith, D.R. and Mukhopadhyay, S. (2017) Hypothyroidism induced by loss of the manganese efflux transporter SLC30A10 may be explained by reduced thyroxine production. J. Biol. Chem. 292, 16605-16615.

(17) Mukhopadhyay, S., Bachert, C., Smith, D.R. and Linstedt, A.D. (2010) Manganeseinduced trafficking and turnover of the cis-Golgi glycoprotein GPP130. Mol. Biol. Cell 21, $1282-1292$.

(18) Mukhopadhyay, S. and Linstedt, A.D. (2011) Identification of a gain-of-function mutation in a Golgi P-type ATPase that enhances Mn2+ efflux and protects against toxicity. Proc. Natl. Acad. Sci. U. S. A. 108, 858-863.

(19) Mukhopadhyay, S. and Linstedt, A.D. (2012) Manganese blocks intracellular trafficking of Shiga toxin and protects against Shiga toxicosis. Science 335, 332-335.

(20) Roudeau, S., Carmona, A., Perrin, L. and Ortega, R. (2014) Correlative organelle fluorescence microscopy and synchrotron X-ray chemical element imaging in single cells. Anal. Bioanal. Chem. 406, 6979-6991.

(21) Carmona, A., Roudeau, S., Perrin, L., Veronesi, G. and Ortega, R. (2014)

Environmental manganese compounds accumulate as Mn(II) within the Golgi apparatus of dopamine cells: relationship between speciation, subcellular distribution, and cytotoxicity. Metallomics 6, 822-832.

(22) Boesenberg, U., Ryan, C.G., Kirkham, R., Siddons, D.P., Alfeld, M., Garrevoet, J., Núñez, T., Claussen, T., Kracht, T. and Falkenberg, G. (2016) Fast X-ray microfluorescence imaging with submicrometer-resolution integrating a Maia detector at beamline P06 at PETRA III. J. Synchrotron Radiat. 23, 1550-1560. 
(23) Perrin, L., Carmona, A., Roudeau, S. and Ortega, R. (2015) Evaluation of sample preparation methods for single cell quantitative elemental imaging using proton or synchrotron radiation focused beams. J. Anal. At. Spectrom. 30, 2525-2532.

(24) Ortega, R., Carmona, A., Roudeau, S., Perrin, L., Dučić, T., Carboni, E., Bohic, S., Cloetens, P. and Lingor, P. (2016) $\alpha$-Synuclein over-expression induces increased iron accumulation and redistribution in iron-exposed neurons. Mol. Neurobiol. 53, 1925-1934.

(25) Da Silva, J.C., Pacureanu, A., Yang, Y., Bohic, S., Morawe, C., Barett, R. and Cloetens, P. (2017) Efficient concentration of high-energy x-rays for diffraction-limited imaging resolution. Optica 4, 492-495.

(26) Perrin, L., Roudeau, S., Carmona, A., Domart, F., Petersen, J.D., Bohic, S., Yang, Y., Cloetens, P. and Ortega, R. (2017) Zinc and copper effects on stability of tubulin and actin networks in dendrites and spines of hippocampal neurons. ACS Chem. Neurosci. 8, 14901499.

(27) Carmona, A., Devès, G., Roudeau, S., Cloetens, P., Bohic, S. and Ortega, R. (2010) Manganese accumulates within Golgi apparatus in dopaminergic cells as revealed by synchrotron x-ray fluorescence nanoimaging. ACS Chem. Neurosci. 1, 194-203.

(28) Ortega, R. (2011) Direct speciation analysis of inorganic elements in single cells using X-ray absorption spectroscopy. J. Anal. Spectrom. 26, 23-29.

(29) Morello, M., Canini, A., Mattioli, P., Sorge, R.P., Alimonti, A., Bocca, B., Forte, G., Martorana, A., Bernardi, G. and Sancesario, G. (2008) Sub-cellular localization of manganese in the basal ganglia of normal and manganese-treated rats: An electron spectroscopy imaging and electron energy-loss spectroscopy study. Neurotoxicology 29, 60-72.

(30) Kalia, K., Jiang, W. and Zheng, W. (2008) Manganese accumulates primarily in nuclei of cultured brain cells. Neurotoxicology 29, 466-470.

(31) Chwiej, J., Szczerbowska-Boruchowska, M., Lankosz, M., Wojcik, S., Falkenberg, G., Stegowski, Z. and Setkowicz, Z. (2005) Preparation of tissue samples for X-ray fluorescence microscopy. Spectrochim. Acta Part B At. Spectrosc. 60, 1531-1537.

(32) Matsuyama, S., Shimura, M., Mimura, H., Fujii, M., Yumoto, H., Sano, Y., Yabashi, M., Nishino, Y., Tamasaku, K., Ishikawad, T. and Yamauchie, K. (2009) Trace element 
mapping of a single cell using a hard x-ray nanobeam focused by a Kirkpatrick-Baez mirror system. X-Ray Spectrom. 38, 89-94.

(33) Matsuyama, S., Shimura, M., Fujii, M., Maeshima, K., Yumoto, H., Mimura, H., Sano, Y., Yabashi, M., Nishino, Y., Tamasaku, K., Ishizaka, Y., Ishikawa, T. and Yamauchi, K. (2010) Elemental mapping of frozen-hydrated cells with cryo-scanning X-ray fluorescence microscopy. X-Ray Spectrom. 39, 260-266.

(34) Hackett, M.J., McQuillan, J.A., El-Assaad, F., Aitken, J.B., Levina, A., Cohen, D.D., Siegele, R., Carter, E.A., Grau, G.E., Hunt, N.H. and Lay, P.A. (2011) Chemical alterations to murine brain tissue induced by formalin fixation: implications for biospectroscopic imaging and mapping studies of disease pathogenesis. Analyst 136, 2941-2952.

(35) Leoni, L., Dhyani, A., La Riviere, P., Vogt, S., Lai, B. and Roman, B.B. (2011) $\beta$-Cell subcellular localization of glucose-stimulated Mn uptake by X-ray fluorescence microscopy: implications for pancreatic MRI. Contrast. Media Mol. Imaging 6, 474-481.

(36) Dučić, T., Barski, E., Salome, M., Koch, J.C., Bähr, M. and Lingor, P. (2013) X-ray fluorescence analysis of iron and manganese distribution in primary dopaminergic neurons. $J$. Neurochem. 124, 250-261.

(37) Daoust, A., Saoudi, Y., Brocard, J., Collomb, N., Batandier, C., Bisbal, M., Salomé, M., Andrieux, A., Bohic, S. and Barbier, E.L. (2014) Impact of manganese on primary hippocampal neurons from rodents. Hippocampus 24, 598-610.

(38) Dučić, T., Carboni, E., Lai, B., Chen, S., Michalke, B., Lázaro, D.F., Outeiro, T.F., Bähr, M., Barski, E. and Lingor, P. (2015) Alpha-synuclein regulates neuronal levels of manganese and calcium. ACS Chem. Neurosci. 6, 1769-1779.

(39) Van Baelen, K., Vanoevelen, J., Callewaert, G., Parys, J.B., De Smedt, H., Raeymaekers, L., Rizzuto, R., Missiaen, L. and Wuytack, F. (2003) The contribution of the SPCA1 Ca2+ pump to the Ca2+ accumulation in the Golgi apparatus of HeLa cells assessed via RNA-mediated interference. Biochem. Biophys. Res. Commun. 306, 430-436.

(40) Micaroni, M., Perinetti, G., Berrie, C.P. and Mironov, A.A. (2010) The SPCA1 Ca2+ pump and intracellular membrane trafficking. Traffic 11, 1315-1333. 
(41) Leitch, S., Feng, M., Muend, S., Braiterman, L.T., Hubbard, A.L. and Rao, R. (2011) Vesicular distribution of secretory pathway $\mathrm{Ca}^{2}+$-ATPase isoform 1 and a role in manganese detoxification in liver-derived polarized cells. Biometals 24, 159-170.

(42) Zhao, Y., Feresin, R.G., Falcon-Perez, J.M. and Salazar, G. (2016) Differential targeting of SLC30A10/ZnT10 heterodimers to endolysosomal compartments modulates EGF-induced MEK/ERK1/2 activity. Traffic 17, 267-288.

(43) Selyunin, A.S., Iles L.R., Bartholomeusz, G. and Mukhopadhyay, S. (2017) Genomewide siRNA screen identifies UNC50 as a regulator of Shiga toxin 2 trafficking. J. Cell Biol. $216,3249-3262$.

(44) Selyunin, A.S. and Mukhopadhyay, S. A. (2015) Conserved structural motif mediates retrograde trafficking of Shiga toxin types 1 and 2. Traffic 16, 1270-1287.

(45) Carmona, A., Devès, G. and Ortega, R. (2008) Quantitative micro-analysis of metal ions in subcellular compartments of cultured dopaminergic cells by combination of three ion beam techniques. Anal. Bioanal. Chem. 390, 1585-1594.

(46) Carmona, A., Cloetens, P., Devès, G., Bohic, S. and Ortega, R. (2008) Nano-imaging of trace metals by synchrotron X-ray fluorescence into dopaminergic single cells and neuritelike processes. J. Anal. At. Spectrom. 23, 1083-1088.

(47) Ryan, C.G., Laird, J.S., Fisher, L.A., Kirkham, R. and Moorhead, G.F. (2015) Improved dynamic analysis method for quantitative PIXE and SXRF element imaging of complex materials. Nucl. Instrum. Methods Phys. Res. B 363, 42-47.

(48) Solé, V.A., Papillon, E., Cotte, M., Walter, P. and Susini, J. (2007) A multiplatform code for the analysis of energy-dispersive X-ray fluorescence spectra. Spectrochim. Acta Part B 62, 63-68. 